\title{
História da Matemática e suas potencialidades pedagógicas em salas de aula do Ensino Fundamental
}

\author{
Ana Catarina Cantoni Roque \\ Professora, IFMG - Campus Governador Valadares \\ anacant@gmail.com
}

\author{
Maria Laura Magalhães Gomes \\ Professora, UFMG \\ mlauramgomes@gmail.com
}

\begin{abstract}
Resumo
Neste artigo, apresentamos os principais resultados de uma investigação que teve como um de seus objetivos a identificação das potencialidades pedagógicas da História da Matemática que se tornam mais evidentes em uma situação real de sala de aula. A investigação foi realizada em turmas de sétimo ano do Ensino Fundamental nas quais foram propostas, em um trabalho cooperativo com a professora, atividades relacionadas à História da Matemática referentes ao tema "Números Inteiros". A análise do material empírico mostrou que a História foi uma fonte de motivação para o ensino-aprendizagem da Matemática, constituiu-se como fonte de métodos pedagogicamente adequados e interessantes para a abordagem dos números inteiros e trouxe contribuições para a prática didática da professora. A pesquisa também mostrou que existem algumas dificuldades para integrar a História da Matemática às práticas pedagógicas.
\end{abstract}

Palavras-chave: História da Matemática. Potencialidades pedagógicas da História da Matemática. Números Inteiros. Ensino Fundamental. Dificuldades de integração da História da Matemática à prática pedagógica.

\section{History of Mathematics and its pedagogical potentialities in classrooms of elementary school}

\begin{abstract}
This article presents the main results of an investigation which had as one of its objectives to identify the pedagogical potentialities of the history of mathematics that become more evident in a real classroom. The research was conducted in classes of seventh year of elementary school in which we proposed activities related to the history of mathematics concerning the theme "Integers" working cooperatively with the teacher. The empirical analysis showed that history was a source of motivation for teaching and learning mathematics, was constituted as a source of pedagogically appropriate and interesting methods for dealing with the integers and made contributions to the teacher's practice. The investigation also showed that there are some difficulties in integrating the history of mathematics to pedagogical practices.
\end{abstract}

Keywords: History of Mathematics. Pedagogical potentialities of History of Mathematics. Integers. Elementary School. Difficulties of integrating History of Mathematics to Pedagogical Practices. 


\section{Introdução}

No Brasil, as considerações sobre a pertinência da inserção de elementos históricos no ensino de Matemática têm sido explicitadas desde, pelo menos, a década de 1930, no contexto da Reforma Francisco Campos (1931). Naquela época, autores de livros didáticos incorporaram em suas obras as orientações dessa reforma referentes à presença de aspectos do desenvolvimento dos conhecimentos matemáticos ao longo do tempo (MIGUEL; MIORIM, 2004).

Durante o momento de predomínio das ideias do Movimento da Matemática Moderna, nas décadas de 1960 e 1970, a integração da História da Matemática ao ensino não era vista com um olhar favorável (VIANNA, 1995). Já nos anos finais da década de 1980, as críticas a esse movimento começaram a se intensificar e houve um aumento das manifestações em favor da presença da História em textos voltados à prática pedagógica em Matemática. Assim, a partir da década de 1990, ampliou-se o trabalho com elementos históricos em produções brasileiras destinadas à matemática escolar (MIGUEL; MIORIM, 2004).

Hoje, podemos constatar a presença de referências à História da Matemática na maioria dos livros didáticos e também em livros paradidáticos publicados no Brasil, especialmente naqueles que se destinam à Educação Básica. As relações entre História e Educação Matemática também têm sido tema de pesquisa de grupos brasileiros e muitos pesquisadores têm apresentado seus trabalhos em eventos de Educação Matemática realizados no país ${ }^{1}$.

As preocupações com a inserção da História no ensino-aprendizagem da Matemática também estão presentes nos Parâmetros Curriculares Nacionais (PCN), proposta publicada no final da década de 1990, que tem como objetivo subsidiar a elaboração de currículos para a Educação Básica no país.

Esse documento aponta várias contribuições que a História pode trazer para o processo de ensino-aprendizagem da Matemática, algumas das quais também são discutidas por Miguel (1997). De acordo com os PCN, dentre outras funções, a História da Matemática, ao revelar a Matemática como um criação humana, relacionada às preocupações e necessidades de diferentes culturas, em diferentes momentos históricos, pode auxiliar na compreensão das relações entre os avanços tecnológicos de hoje e a herança cultural das gerações passadas; pode desempenhar o papel de uma fonte de caminhos diferenciados para a abordagem de conceitos matemáticos e ser um veículo de informação cultural, sociológica e antropológica de grande valor formativo.

1. Pode-se constatar isso, por exemplo, numa rápida consulta aos anais das últimas edições do Encontro Nacional de Educação Matemática (ENEM). 
No entanto, esse documento finaliza sua consideração sobre o uso da História da Matemática como um recurso didático alertando que, nessa abordagem, não é suficiente o professor "situar no tempo e no espaço cada item do programa de Matemática ou contar sempre em suas aulas trechos da história da Matemática" (BRASIL, 1998, p.43). O que se propõe é que o docente encare a história "como um recurso didático com muitas possibilidades para desenvolver diversos conceitos, sem reduzi-la a fatos, datas e nomes a serem memorizados" (Idem).

$\mathrm{Na}$ literatura pertinente, podemos encontrar argumentos reforçadores e questionadores das potencialidades pedagógicas da História da Matemática (FAUVEL e VAN MAANEN, 2000; MIGUEL, 1997; MIGUEL e MIORIM, 2004; VIANNA, 1995). Alguns argumentos contrários à incorporação da História na Educação Matemática são apresentados por Tzanakis, Arvavi et al (2000), Miguel (1997) e Vianna (1995). De acordo com Tzanakis, Arcavi et al (2000), esses argumentos se baseiam em pelo menos dois tipos de dificuldades: filosóficas e práticas. Dificuldades de caráter filosófico são, por exemplo, a consideração de que a História pode ser mais tortuosa e confusa do que esclarecedora e a de que muitos estudantes não gostam de História e, assim, não gostarão de História da Matemática ou não a acharão menos aborrecida do que a Matemática.

As objeções de ordem prática se relacionam a quatro tipos de lacunas:

1) a lacuna do tempo: não há tempo suficiente em sala de aula para o aprendizado da Matemática e ele é ainda menor quando se propõe ensinar também a História da Matemática;

2) a lacuna dos recursos: não existem recursos materiais apropriados suficientes para ajudar aqueles professores que poderiam querer integrar informações históricas ao ensino da Matemática;

3) a lacuna da especialidade: para se integrar a História ao ensino não só conhecimentos históricos são requeridos, mas também conhecimentos interdisciplinares, o que vai além do conhecimento de que os professores de matemática estão equipados;

4) a lacuna da avaliação: não existe uma forma clara ou consistente para integrar um componente histórico na avaliação dos estudantes, e se esse não for avaliado, os estudantes não valorizarão ou darão atenção a ele (TZANAKIS; ARCAVI et al., 2000, p. 203).

Já os argumentos favoráveis à integração da História da Matemática ao ensino de Matemática são vários. Miguel (1997) nos apresenta uma síntese desses argumentos, dentre os quais destacamos: 
1) A História é uma fonte de motivação para o ensino-aprendizagem da matemática;

2) a História pode servir de apoio para se atingir, com os alunos, objetivos pedagógicos que os levem a perceber, dentre outras coisas: a matemática como uma criação humana; as razões pelas quais as pessoas fazem matemática; as necessidades práticas, sociais, econômicas e físicas que servem de estímulo ao desenvolvimento da matemática;

3) a História constitui-se numa fonte de métodos pedagogicamente adequados e interessantes para a abordagem de certos campos ou tópicos matemáticos;

4) a História é um instrumento que pode promover a aprendizagem significativa e compreensiva da matemática.

Em conformidade com o terceiro argumento apresentado por Miguel, Katz et al. (2000) apresentam alguns estudos que têm mostrado que certas dificuldades encontradas pelos estudantes no processo de ensino-aprendizagem da Matemática são análogas às enfrentadas pelos produtores de conhecimentos. Diante dessa constatação, esses autores afirmam que

[...] um professor que tem conhecimento da História da Matemática antecipará as dificuldades dos alunos em áreas nas quais, historicamente, muito trabalho foi necessário para ultrapassar dificuldades significativas. Assim, o professor pode estar preparado com estratégias de ensino apropriadas para essas situações, algumas delas bem podem estar de acordo com os desenvolvimentos históricos e ajudarão os alunos a superar os obstáculos à compreensão" (KATZ et al., 2000, p.153).

Tzanakis, Arcavi et al. (2000) também afirmam que a prática didática de professores e seu repertório pedagógico pode ser enriquecido e aperfeiçoado mediante a interação com a História da Matemática no processo educacional.

Acreditamos ser importante considerar os argumentos reforçadores e questionadores das potencialidades pedagógicas da História da Matemática presentes na literatura para não termos a ingenuidade de assumir que a História é a solução para todos os problemas do ensino da Matemática. Comungamos, porém, da mesma opinião de Miguel e Miorim no sentido de que a História, desde que constituída para fins pedagógicos e articulada com as demais variáveis que intervêm no processo de ensino-aprendizagem, pode trazer contribuições significativas para a Matemática escolar.

Partindo desse pressuposto, a História da Matemática pode ser incorporada ao processo de ensino-aprendizagem da Matemática que ocorre em sala de aula de maneira 
implícita ou explícita. De acordo com Ferreira e Rich (2001, apud Dambros, 2006), a participação implícita ocorre quando a História é utilizada como um sinalizador do caminho a ser seguido e a explícita quando a ênfase é colocada na própria História.

Iran Mendes, com base num trabalho desenvolvido há mais de 15 anos, defende o uso de uma abordagem histórica e investigatória nas aulas de Matemática como alternativa pedagógica para a realização de um ensino significativo. Para esse autor, quando as informações históricas são investigadas, interpretadas, experimentadas e analisadas, "os estudantes iniciam um processo de elaboração mental e simbólica que favorece a abstração dos conceitos matemáticos investigados" (MENDES, 2009, p. VII).

Neste artigo, trazemos alguns resultados de uma pesquisa de mestrado quanto às potencialidades pedagógicas da presença da História no ensino-aprendizagem da Matemática ${ }^{2}$. Nessa pesquisa, dialogamos com os estudos realizados pelos teóricos da aprendizagem situada. A perspectiva da aprendizagem situada se origina nos estudos de Lave (1996), Lave e Wenger (1991) e Wenger (1998), e nela, diferentemente das teorias que reduzem a aprendizagem a capacidades e atividades mentais individuais, a aprendizagem passa a ser vista como "um fenômeno situado e construído socialmente" (MATOS, 1999, p. 67). Assim, o conhecimento deixa de ser representado como uma característica individual que pode ser desenvolvida e, então, usada em diferentes situações, e passa a ser representado, de acordo com Boaler (2002, p. 42), "como algo que está distribuído entre as pessoas, atividades e sistemas do seu ambiente”.

\section{Contexto e metodologia}

Os dados aqui apresentados foram obtidos por meio da observação participante realizada pela primeira autora em turmas de $7^{\circ}$ ano do Ensino Fundamental de uma escola da Rede Municipal de Educação de Belo Horizonte.

Em um trabalho cooperativo ${ }^{3}$ com a professora das turmas, Josi, foram elaboradas e aplicadas seis atividades, todas com referência à história dos números inteiros. As atividades foram planejadas de tal maneira que as mesmas se relacionas-

2. Em um texto anterior (ROQUE; GOMES, 2011), apresentamos um estudo preliminar ao do presente artigo no qual se relata uma experiência em turmas de $7^{\circ}$ ano do Ensino Fundamental sob a regência da primeira autora. Esse estudo, cujo objetivo foi subsidiar a investigação de mestrado desenvolvida posteriormente, difere do trabalho que ora apresentamos, como o leitor poderá conferir, tanto nos métodos quanto nos resultados.

3. Esclarecemos que trabalho cooperativo está sendo entendido como um trabalho no qual os participantes cooperam com o pesquisador na realização da pesquisa, mas as finalidades das tarefas realizadas não resultam de negociação conjunta, podendo haver relações desiguais de alguns em relação a outros (FIORENTINI, 2006, FIORENTINI; LORENZATO, 2007). 
sem com o conteúdo curricular do $7^{\circ}$ ano e pudessem ser inseridas de modo natural no planejamento da professora. Além disso, ao elaborar as atividades, tomou-se o cuidado de fazer com se evidenciassem relações entre elas, para que cada uma fosse percebida como em continuidade com as anteriores.

Para complementar e subsidiar a interpretação dos resultados, aplicamos dois questionários aos alunos, relacionados ao tema das atividades, e realizamos entrevistas com a professora e com alguns estudantes.

A observação participante aconteceu em aulas anteriores à aplicação das atividades, nas aulas em que as atividades foram desenvolvidas e em aulas intermediárias sem a presença das atividades.

De maneira geral, o desenvolvimento das atividades se dava da seguinte maneira: a professora introduzia o trabalho fazendo uma discussão coletiva, com os alunos assentados individualmente. A seguir, ela pedia que os estudantes realizassem as tarefas propostas; em algumas ocasiões, eles se assentavam em dupla. Sugerimos que alguma atividade fosse feita em grupo, mas Josi não aceitou a proposta, alegando que, com mais de dois alunos reunidos, ocorre muita confusão e nem todos fazem a atividade. No entanto, ela permitia que as duplas conversassem entre si. Terminada a realização das tarefas por parte dos alunos, havia um novo momento de discussão e correção coletiva das tarefas propostas envolvendo a turma como um todo.

O primeiro questionário foi aplicado antes de a professora introduzir os números inteiros e tinha como objetivos: investigar se os alunos já haviam tido algum acesso a informações relacionadas à História da Matemática e investigar suas concepções sobre a natureza da Matemática.

$\mathrm{Na}$ primeira atividade, a História foi integrada de maneira explícita ao processo de ensino-aprendizagem mediante o fornecimento de informações diretas aos alunos. Tal atividade consistiu na leitura e discussão de um texto, elaborado pela professora Josi, com algumas informações sobre a história dos números inteiros. Os principais objetivos dessa atividade eram levar os alunos a compreenderem que o conhecimento matemático é desenvolvido pela humanidade ao longo do tempo e que esse processo, como no caso dos números negativos, pode ser cercado por dúvidas e incertezas, de tal forma que os próprios matemáticos podem ter dificuldades na compreensão de conceitos. Consideramos que essa conscientização poderia levar os estudantes a terem uma postura mais favorável diante dos conhecimentos matemáticos.

$\mathrm{Na}$ segunda atividade, que tinha como objetivo permitir que os alunos conhecessem e experimentassem um antigo método de escrita de números tendo como referência uma outra perspectiva cultural, que se diferencia da ocidental, à qual 
eles estão acostumados, a História também esteve presente de maneira explícita. Nela, os estudantes foram apresentados a um antigo sistema de numeração chinês, chamado sistema de numeração de Shang. Esse sistema de numeração era decimal e posicional e nele os números maiores do que nove eram representados alternando-se as formas vertical e horizontal dos algarismos de um a nove. Durante séculos, foram utilizadas varas de contagem para representar esses números (BEERY et al., 2004). A notação nesse sistema de números, que incluía uma forma específica para indicar números negativos, foi apresentada aos alunos, que tiveram a oportunidade de praticar a escrita de diferentes números de acordo com ela.

A terceira e a quarta atividade tiveram como objetivos, respectivamente, introduzir a adição e a subtração de números inteiros tendo como referência a maneira pela qual os antigos chineses realizavam seus cálculos, ou seja, manipulando varetas pretas para representar números positivos e varetas vermelhas para representar números negativos. ${ }^{4}$ Nelas, a História esteve presente, predominantemente, de maneira explícita,

Na quinta atividade trabalhamos com o quadro de contagem chinês ${ }^{5}$, estabelecendo como objetivo que os alunos aprendessem a realizar adição e subtração de inteiros utilizando o sistema de numeração de Shang. Esperávamos também que tal atividade contribuísse para revisar e melhorar o entendimento dos alunos a respeito dos sistemas de numeração decimais e da adição e subtração de inteiros.

$\mathrm{Na}$ sexta atividade, a História esteve presente tanto de maneira implícita quanto explícita. Nela, com o objetivo de tentar humanizar a Matemática, no sentido de que os alunos percebessem que as pessoas que a desenvolvem são seres humanos comuns, foi trabalhado um texto introdutório com um breve relato sobre a vida de Euler. A seguir, considerando que a observação de padrões foi uma das maneiras pelas quais Euler frequentemente deduziu regras matemáticas (BEERY et. al., 2004), os alunos foram levados a descobrir a regra dos sinais para a multiplicação e divisão de inteiros pela observação de padrões em sequências de resultados de multiplicações e divisões.

O segundo questionário foi aplicado após o desenvolvimento das seis atividades e tinha como finalidade obter informações que nos auxiliassem a analisar as potencialidades pedagógicas da História da Matemática presentes em nossa pesquisa de campo e também a participação dos alunos nessas atividades.

4. Para a realização da terceira, quarta e quinta atividades, os alunos utilizaram palitos de fósforo pintados de preto e vermelho que foram confeccionados pela primeira autora e pela professora.

5. Para a realização dessa atividade, confeccionamos para a professora e para os alunos versões dos quadros de contagem que os antigos chineses utilizavam para realizar seus cálculos. 


\section{Dificuldades para integrar a História da Matemática às práticas pedagógicas}

Ao longo de nossa investigação, vivenciamos duas das dificuldades de incorporar a História à prática pedagógica mencionadas por Tznakis, Arcavi et al. (2000).

A primeira delas se relaciona à lacuna dos recursos, e consistiu na dificuldade de encontrar materiais produzidos no Brasil que pudessem nos auxiliar na elaboração de atividades especificamente relacionadas à história dos números negativos. Nossa principal referência acabou se tornando um material produzido nos Estados Unidos, cuja tradução para a língua portuguesa foi feita por nós. Ainda com relação a esse tipo de lacuna, embora a internet propicie um maior acesso a materiais relacionados à História do que havia antes, minimizando um pouco o problema, esse recurso ainda não está disponível a todos os professores brasileiros. Além disso, como a professora Josi nos apontou, há outros tipos de problemas com os quais os professores se deparam no seu dia a dia e que, de certa forma, se relacionam à dificuldade de buscar esses recursos:

Josi: E outro problema muito grande também: olha, hoje, graças a Deus, a gente tem internet pra buscar essas informações. Eu busquei os textos na internet, mas na biblioteca dessa escola mesmo não tem. Não tem livro paradidático, não. O professor pode até ter interesse em ir buscar, mas não tem acesso fácil a essas informações. [...] Então são várias as dificuldades no dia a dia que o professor enfrenta: o acesso não é fácil, às vezes ele trabalha dois horários e não tem tempo pra isso. [Entrevista em 20 de maio de 2011]

Uma outra dificuldade que encontramos diz respeito à lacuna da especialidade. Para que o professor possa investir na integração da História ao processo de ensino-aprendizagem, é necessário que ele tenha também conhecimentos históricos e não apenas conhecimentos matemáticos. No entanto, esses conhecimentos, muitas vezes, ainda são negligenciados ou trabalhados de forma insatisfatória nos cursos de formação inicial dos docentes. Assim, mesmo que o professor reconheça que a História é um elemento importante e enriquecedor para o ensino, os conhecimentos históricos ainda estão distantes das salas de aula, conforme nos relata Gomes (2005), e é reforçado pela fala de Josi:

Josi: Sim, eu vejo ela [História da Matemática] também como uma estratégia de ensino. O problema é que a gente tem pouco conhecimento. Eu falo de mim, como professora, e as pessoas que eu tenho contato que também são professores de matemática. Poucos professores exploram esse lado, da História da Matemática. [Entrevista em 31 de janeiro de 2011] 
Essa falta de formação histórica também é responsável por outros tipos de dificuldades que se relacionam à lacuna da especialidade, como a apontada pela professora Josi na fala a seguir:

Josi: E olha, quando eu fui ler um pouco sobre o surgimento dos números, que eu tive que ensinar essa matéria, você vê que também há muitos desencontros entre textos... um texto escrevia de uma forma, outro texto escrevia de outra, há divergência, assim, de informações. Algumas informações não batem com informações de outros autores, então não há consenso. [...] Mas como é que os professores vão saber quem é mais confiável? [Entrevista em 20 de maio de 2011]

\section{Potencialidades pedagógicas que se fizeram presentes}

Dentre as potencialidades pedagógicas da História da Matemática que se evidenciaram em nossa investigação, escolhemos três para discutir neste texto: a História como fonte de motivação, a História como fonte de métodos pedagogicamente adequados e interessantes para a abordagem de certos campos ou tópicos matemáticos e a História como contribuição para a prática didática.

\section{A História como fonte de motivação}

Tzanakis, Arcavi et al (2000) afirmam que a História da Matemática fornece uma ampla ampla gama de problemas, questões e formas de exposição que podem ser muito valiosas para motivar, interessar e engajar o aluno, contribuindo, assim, para a aprendizagem. Essa ideia está de acordo com a potencialidade discutida por Miguel (1997), segundo a qual a História pode representar uma fonte de motivação para o ensino-aprendizagem da Matemática.

Em nossa investigação, os alunos se mobilizaram de maneira intensa na maioria das atividades relacionadas à História e muitos deles se manifestaram mais do que em outras aulas de Matemática. Tal fato nos levou a acreditar que a presença da História, de algum modo, motivou os estudantes. De fato, os relatos dos alunos no questionário final e nas entrevistas nos permitiram concluir que eles realmente se sentiram motivados pelas atividades propostas por nós. Nas falas a seguir, é possível perceber, especialmente nos trechos destacados, que os alunos demonstraram envolvimento, pois comentam o que haviam feito com certa emoção e vibração. Fica evidente também, que eles perceberam que as atividades foram diferentes daquelas a que estavam acostumados em seu cotidiano. 
Douglas $^{6}$ : Eu aprendi muitas coisas, como por exemplo os números chineses, como fazer conta utilizando eles, aprendi a fazer contas com palitos, eu achei isso interessante, inovador, legal e inteligente. Achei legal saber quem é Euler e saber o que ele fazia, saber como ele era. [Questionário Final dia 17 de maio de 2011]

Saiury: Eu achei muito interessante como a professora explicou a matéria, ela trouxe coisas novas. [...] está sendo interessante pra mim, mais fácil do que as outras matérias. É legal ter coisas inovadoras para incentivar os alunos a estudar e se concentrarem. [Questionário Final dia 17 de maio de 2011]

Um fato interessante é que a História motivou não apenas os alunos, mas também a professora, como se pode perceber na fala a seguir:

Josi: E eu não sei te dizer de qual atividade eu gostei mais, eu gostei do conjunto, porque uma coisa foi levando à outra, e como eu te falei, da forma como foi feito. [Entrevista em 31 de janeiro de 2011]

\section{A História como fonte de métodos pedagogicamente adequados e interessantes para a abordagem de certos campos ou tópicos matemáticos}

Em nosso trabalho, a atividade referente à adição de inteiros utilizando varas de contagem chinesas se destacou no que diz respeito à História como uma fonte de métodos para o trabalho pedagógico e como um instrumento relevante para a aprendizagem da Matemática.

A técnica de cálculo com varas de contagem chinesas, trabalhada nessa atividade, de acordo com o relato de alguns alunos e da professora, propiciou uma aprendizagem mais significativa da Matemática, na medida em que contribuiu para que os alunos entendessem o significado da operação de adição:

Seu Zé: É muito mais fácil fazer com os palitos, ah, não sei, você consegue, você consegue ver mais fácil a conta, a operação aí já acha a resposta. [Entrevista dia 20 de maio de 2011]

Sophia: Eu achei muito interessante essas atividades que a professora passou. Achei muito mais fácil fazer cálculos com palitos pretos e vermelhos pois podemos visualizar o que estamos fazendo de uma forma melhor. [Questionário Final dia 13 de maio de 2011]

6. Os nomes de todos os alunos são fictícios e foram escolhidos por eles mesmos. 
Segundo a professora Josi, o uso de materiais concretos auxiliou na aprendizagem dos alunos, mas a História foi importante para os alunos "verem que aquilo fazia parte de um contexto, não surgiu do nada" e para mostrar o desenvolvimento do conteúdo.

O método de cálculo trabalhado nessa atividade também ajudou os estudantes a saberem, em cada caso, qual sinal deveria ser colocado após a eliminação dos parênteses, no caso da adição, e qual operação deveria ser feita com os valores absolutos dos números para se chegar ao resultado. Acreditamos que esse fato contribuiu para uma aprendizagem significativa por parte dos alunos.

Outro fator interessante é que, mesmo após a professora introduzir outras ideias para operar com inteiros, como dívidas e bens ou débitos e créditos, muitos alunos continuaram a utilizar as ideias relacionadas a esse método para efetuar os cálculos. O diálogo a seguir, que ocorreu em uma aula em que a professora estava corrigindo um exercício do livro didático, várias aulas após a aplicação da terceira atividade, ilustra isso:

Josi: Gente, na letra $\mathrm{C}$ não é um número negativo com um número positivo? Alunos: É.

Josi: Uma soma de um número positivo com um número negativo.

Lucas: Faz com os palitinhos.

Josi: Quando é um positivo com um negativo, na adição o quê que a gente faz? Michel: Soma.

Joyce: Junta os palitinhos.

Josi: Soma um positivo com um negativo.

Bruno: Não. Junta os palitinhos pretos com os vermelhos e o que sobrar ... Lucas: Junta os vermelhos com os pretos e vai tirando os pauzinhos... [fala fazendo os gestos de juntar e tirar.]

Julius: Aí no final o que sobrar...

Josi: Tá, tô entendendo. Vocês estão falando o que acontece com os palitinhos. Gente, mas agora eu já quero a regra de calcular. Eu não vou ficar toda vida falando de palitinhos.

Lucas: Eu vou. Da hora. Mais fácil.

[Aula de 17 de março de 2011]

Essa última fala do aluno Lucas deixa claro que ele continuou a usar esse método porque o considerou eficaz. Outros alunos relataram, no questionário final e nas entrevistas, que essa atividade ajudou no aprendizado, como Karynna: 
Eu achei que os números escrito em chinês foi bom para mim porque é mais fácil e também aprender outras formas de escrever os números. No caso dos palitos pretos e vermelhos, foi a melhor coisa que a professora de Matemática fez porque ajudou a resolver as contas precisas melhor. [Questionário final aplicado em 17 de maio de 2011]

Embora não tenhamos dúvida de que o uso dos palitos coloridos como um material concreto tenha desempenhado um importante papel, estamos convencidas de que, caso tivéssemos aplicado a mesma atividade sem levar em consideração todo o contexto histórico trabalhado anteriormente, não obteríamos os mesmos resultados. De fato, foi apenas depois de estudar aspectos históricos ligados aos números inteiros, particularmente após conhecermos a maneira como os antigos chineses representavam números positivos e negativos, que concebemos a ideia de utilizar os palitos coloridos para trabalhar as operações com inteiros. Além disso, as falas dos estudantes e também a da professora nos indicam que a História contribuiu para que os alunos percebessem que a ideia fazia parte de um contexto. Assim, acreditamos que a atividade não teria o mesmo sentido para os estudantes caso não tivesse sido trabalhada de forma interligada com a História da Matemática.

\section{A História da Matemática contribuindo para a prática didática}

Os aspectos abordados por Tzanakis, Arcavi et al. (2000), Katz et al. (2000) e Mendes (2009), relacionados às contribuições da História da Matemática para a atuação docente também puderam ser percebidos em nosso trabalho.

Conforme a professora Josi nos relatou, o conhecimento de que houve dificuldades, por parte dos matemáticos, em compreender e aceitar os números negativos, foi importante para ela:

Josi: Eu, por exemplo, passei a entender de outra forma essa dificuldade que eles têm. Porque quando você não conhece a história você não imagina que foi tão difícil assim. Pra mim foi uma surpresa quando eu descobri que demorou tantos anos para os números negativos serem aceitos, porque quando a gente vê na escola é tudo muito bonitinho, né? [Entrevista em 20 de maio de 2011]

Esse entendimento também se refletiu em suas aulas, pois, em algumas situações, ela lançou mão da História para mostrar aos alunos que ter dúvidas ao estudar números negativos pode ser normal, justificando as dificuldades apresentadas por eles. A professora enfatizou, ainda, que as atividades desenvolvidas repercutirão em 
sua maneira de abordar esse tema em situações futuras, o que nos leva a considerar que seu repertório didático foi enriquecido.

\section{Considerações Finais}

Em nosso trabalho de campo, várias das potencialidades pedagógicas discutidas por Miguel (1997), Tznakis, Arcavi et al. (2000) e Mendes (2009), dentre outros, puderam ser percebidas.

Destacamos, por exemplo, que a História da Matemática foi uma fonte de motivação para o ensino-aprendizagem da Matemática e se mostrou tanto como uma fonte de métodos pedagogicamente adequados e interessantes para a abordagem dos números negativos quanto como um instrumento capaz de promover a aprendizagem significativa e compreensiva desse conteúdo. Ademais, as atividades trabalhadas em conexão com a História trouxeram contribuições para a prática da professora e enriqueceram seu repertório pedagógico.

Chamamos a atenção para o fato de que a primeira atividade, que se restringiu a apresentar e discutir fatos ligados à história dos números negativos, apesar de ter sido importante para que outras potencialidades se evidenciassem, parece ter despertado menos o interesse dos estudantes do que as demais atividades que propusemos. Tal fato nos remete aos Parâmetros Curriculares Nacionais, segundo os quais não é suficiente o professor "situar no tempo e no espaço cada item do programa de matemática ou contar sempre em suas aulas trechos da História da Matemática". Ao contrário, é necessário que o docente encare a História como um recurso para se ensinar conteúdos sem reduzi-la a fatos, datas e nomes a serem memorizados (BRASIL, 1998, p.43).

Consideramos relevante ressaltar, também, que alguns argumentos contrários à integração da História nas práticas pedagógicas também foram evidenciados em nossa investigação. Trata-se, aqui, especificamente, da constatação quanto à falta de recursos materiais apropriados para ajudar aqueles professores que poderiam querer integrar informações históricas ao ensino, bem como da constatação quanto à falta, por parte do professor, de conhecimentos interdisciplinares necessários para se integrar a História ao ensino.

Para que essas e outras dificuldades sejam superadas, acreditamos que é necessário que historiadores da Matemática, pesquisadores em Matemática e pesquisadores em Educação Matemática se unam com o objetivo de produzir materiais adequados e acessíveis àqueles professores que desejam integrar a História a suas aulas. Ao mesmo tempo, é necessário que se planejem ações no sentido de garantir que a História esteja presente, de maneira conveniente, em cursos de formação 
inicial e continuada de professores, a fim de dar mais subsídios a esse profissional. Finalmente, pensamos que o professor que deseja incluir a História em sua prática não deve desistir diante do primeiro obstáculo.

Destacamos, ainda, que as reflexões advindas dessa investigação trouxeram para nós uma melhor compreensão acerca das contribuições que a História pode trazer para o processo de ensino-aprendizagem da Matemática. Acreditamos que essa experiência também foi esclarecedora e trouxe contribuições para a atuação docente da professora Josi. Esperamos que as discussões provenientes do nosso trabalho possam propiciar subsídios para a prática de outros professores e trazer aportes ao campo de pesquisa que investiga as relações entre a História e a Educação Matemática.

\section{Referências}

BEERY, J. et al. The Story of Negative Numbers. Mathematical Association of America, 2004. CD-ROM. (Historical Modules Project)

BOALER, J. The development of disciplinary relationships: knowledge, practice, and identity in mathematics classrooms. For The Learning of Mathematics. 2002, p. $42-47$.

BRASIL. Secretaria de Educação Fundamental. Parâmetros Curriculares Nacionais: matemática. MEC/SEF, Brasília, 1998. 148p.

DAMBROS, A. A. O conhecimento do desenvolvimento histórico dos conceitos matemáticos e o ensino de Matemática: possíveis relações. Tese (Doutorado em Educação) - Faculdade de Educação, Universidade Federal do Paraná, Curitiba, 2006.

FAUVEL, J; VAN MAANEN, J. (Ed.). History in Mathematics Education: the ICMI study. Dordrecht: Kluwer Academic Publishers, 2000.

FIORENTINI, D. Pesquisar práticas colaborativas ou pesquisar colaborativamente? In: BORBA, Marcelo de Carvalho; ARAÚJO, Jussara de Loyola. Pesquisa qualitativa em Educação Matemática. 2. ed. Belo Horizonte: Autêntica, 2006. p. 49-78.

FIORENTINI, D.; LORENZATO, S. Investigação em educação matemática: percursos teóricos e metodológicos. 2. ed. rev. Campinas: Autores Associados, 2007. (Coleção formação de professores) 
GOMES, E. B. História da Matemática como metodologia de ensino da matemática: perspectivas epistemológicas e evolução de conceitos. 2005. 120f. Dissertação (Mestrado em Ciências e Matemáticas) - Núcleo Pedagógico de Apoio ao Desenvolvimento Científico, Universidade Federal do Pará, Belém, 2005.

KATZ, V. et al. The role of historical analysis in predicting and interpreting students' difficulties in mathematics. In: FAUVEL, J; VAN MAANEN, J. (Ed.). History in Mathematics Education: the ICMI study. Dordrecht: Kluwer Academic Publishers, 2000. p. 149-154.

LAVE, J. Teaching, as Learning, in Practice. Mind, culture and activity, v. 3, n. 3, p. 149-161, 1996.

LAVE, J; WENGER, E. Situaded learning: Legitimate Peripheral Participation. New York: Cambridge University Press, 1991.

MATOS, J.F.L. Aprendizagem e prática social: contributos para a construção de ferramentas de análise da aprendizagem matemática escolar. Actas da II Escola de Verão. Sessão de Educação Matemática da Sociedade Portuguesa de Ciências da Educação. Santarém, 1999.

MENDES, I. A. Investigação histórica no ensino da Matemática. Rio de Janeiro: Ciência Moderna, 2009.

MIGUEL, A. As potencialidades pedagógicas da História da Matemática em questão: argumentos reforçadores e questionadores. Zetetiké, Campinas, v. 5, n. 8, p. 73-105, jul./dez. 1997.

MIGUEL, A.; MIORIM, M. A. História na Educação Matemática: propostas e desafios. Belo Horizonte: Autêntica, 2004. 198p. (Coleção Tendências em Educação Matemática)

ROQUE, A. C. C.; GOMES, M. L. M. História da Matemática na sala de aula. In: XIII Conferência Interamericana de Educação Matemática, 2011, Recife. Anais da XIII CIAEM, 2011. p. 1-12. Disponível em http://www.cimm.ucr.ac.cr/ocs/index. php/xiii_ciaem/xiii_ciaem/paper/view/1198. Acesso em 17 out 2012. 
TZANAKIS, C.; ARCAVI, A. et al. Integrating history of mathematics in the classroom: an analytic survey. In: FAUVEL, J; VAN MAANEN, J. (Ed.). History in Mathematics Education: the ICMI study. Dordrecht: Kluwer Academic Publishers, 2000. p. 201-240.

VIANNA, C. R. Matemática e História: algumas relações e implicações pedagógicas. 1995. 228f Dissertação (Mestrado em Educação Matemática) - Faculdade de Educação, Universidade de São Paulo, São Paulo, 1995.

WENGER, E. Comunities of practice: Learning Meaning and Identity. Cambridge: Cambridge University Press, 1998.

Submetido em setembro de 2012 Aprovado em novembro de 2012 